Bernardo Candela

Department of Fine Arts,

Universidad de La Laguna

\section{Canary lslands Design System: a visual representation of a theoretical, instrumental and operational model}

The concept of Design System can be considered a model that gathers in a single map the dimensions, actors and interrelations a round the Design sector that take place in a delimited territory. Visual interpretations help to graphically represent complex concepts, such as the Design System. Many authors make use of visual interpretations to explain and disseminate their proposals of Design System models.

This poster presents Canary lslands Design System graphic model as a result of capturing the dimensions, actors and interrelations considered part of the system in the Archipelago and it compares various proposals far visual interpretations of the System Design according to its morphology, objective and visualization strategy.
A review of the literature on the theoretical design system models and the documentary study of cases of other territorial realities has been carried out. The initial proposal has been tested through a workshop with stakeholders. Canary lsland Design System allows us to know the state of the art of design as an academic discipline, a professional activity and a creative industry, together with its potential to promote cultural, social and economic development in the Canary lslands.

These have been the preliminary results from the $\mathrm{PhD}$ research. It is still a work in progress. Next steps research will be focus on the visual model refinement, together with its operability. lt is necessary to find representation systems that help visualize the relationships between the actors of the Canary lslands Design System. 
Design System complex networks.

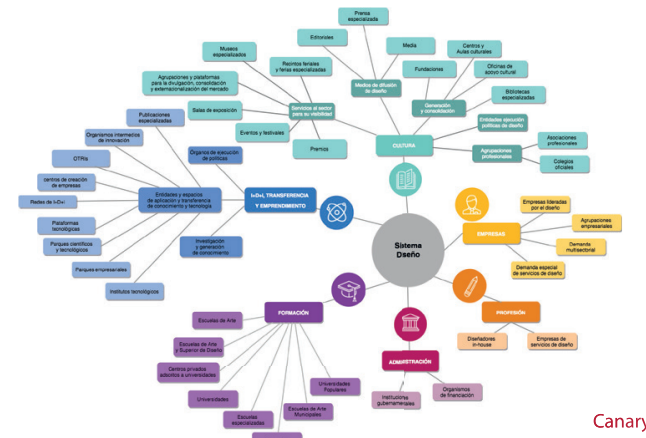

Conclusions

These have been the preliminary results from the $\mathrm{PhD}$ research. It is still a work in progress. Next steps research will be focus on the visual model refinement, together with its operability. It is necessary to find representation systems that help visualize the relationships between the actors of the Canary Islands Design System.

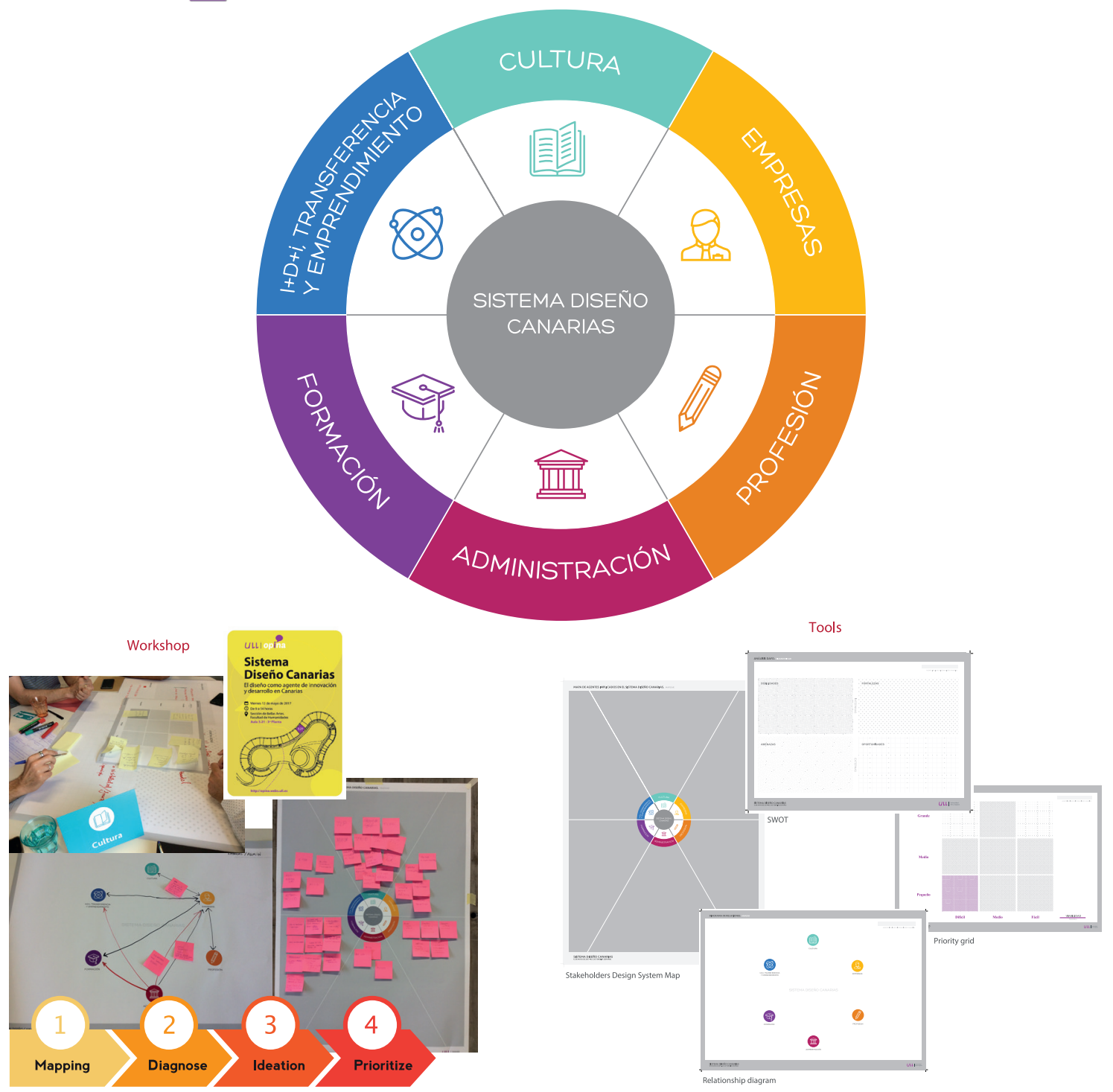

